had been registered for less than three months. The medical records were available for four of the patients registered for 3-12 months and for all the patients registered 12 months or more. Thus, one-quarter $(95 \% \mathrm{CI}$ $14-38 \%$ ) of non-urgent new referrals to a psychiatric outreach clinic had been registered with their GP for less than three months and in no case were the general practice medical records available.

This finding suggested that any association was as likely to be with the lack of medical records as with new registration. In routine cases it takes 8-12 weeks for the new GP to obtain the medical records and this is, on average, four weeks longer when the patient was originally registered outside the Lothians (Primary Care Medical Records, Lothian Health). Most of the delay is accounted for by the time it takes the previous general practice to send the medical records to the new health board.

Verhaak, P. F. N. (1993) Analysis of referrals of mental health problems by general practitioners. British fournol of Generol Proctice, 43, 203-208.

Wilkinson, G. (1989) Referrals from general practitioners to psychiatrists and paramedical mental health professionals. British journal of Psychiotry, 154, 72-76.

T. Glen, A. I. F. Scott Andrew Duncan Clinic, Royal Edinburgh Hospital, Edinburgh EHIO 5HF

\section{Lipid-lowering drugs and mortality}

Sir: In their review paper, Boston et al (1996) reported that increased mortality with cholesterol lowering has been associated with drugs that do not cross the blood/brain barrier, such as cholestyramine, and those that do, such as statins. However, concern about lipid lowering was prompted by studies of drugs other than statins, namely gemfibrozil and cholestyramine (McLoughlin \& Clarke, 1989) and there is evidence that statins are safer. In the West of Scotland Coronary Prevention Study of men with high plasma cholesterol but no history of myocardial infarction, pravastatin reduced the risk of coronary events and the associated deaths without increasing the risk of death from noncardiovascular causes (Shepherd et al, 1995). In a study of myocardial infarction patients who did not have high cholesterol levels, pravastatin reduced non-fatal coronary events with no significant differences in overall mortality or non-cardiovascular mortality (Sacks et al, 1996). In the Scandinavian Simvastatin Survival Study there was a significant reduction in risk of death in the simvastatin group in patients with a previous history of coronary artery disease, an effect apparently independent of baseline serum cholesterol (Scandinavian Simvastatin Survival Study Group, 1995). Further evidence for the safety of statins comes from Wardle et al (1996) who found no changes in tension, anxiety, anger, hostility or depression in patients taking simvastatin compared with those on placebo. The beneficial effects of statins may be due to actions other than cholesterol lowering and the lack of effect on non-cardiac mortality, which contrasts with gemfibrozil and cholestyramine, may also be independent of cholesterol lowering.

There is unlikely to be any ethical way in which to study in humans what other biochemical factors may be altered by the different groups of lipid-lowering drugs. Raised cholesterol concentrations in adults are related to indices of impaired growth during late gestation (Barker et al, 1993) while suicide has been linked with low weight gain in infancy (Barker et al, 1995). Attempts to define biochemical variables associated with violence (including suicide) in adulthood may thus be complicated by an interaction with early nutrition.

Barker, D. J. P., Marty, C. N., Oamond, C., ot of (1993) Growth in utero and serum cholesterol concentrations in adult life. British Medical journal, 307. 1527.

—, Oamond, C., Rodin, l., ex al (1995) Low weight gain in infancy and suicide in adult life. British Medical Journol, 311. 1203

Boston, P. F., Dursun, S. M. \& Reveley, M. A. (1996) Cholesterol and mental disorder. British fournol of Psychiatry. 169, 682-689.

MeLoughtin, I. \& Clarke, P. (1989) Lipid-lowering drugs (letter). British journal of Psychiatry, 154, 275-276.

Sacks, F. M., Pfeffer, M. A., Moye, L. A., ex al (1996) The effect of pravastatin on coronary events after myocardial infarction in patients with average cholesterol levets. New England journal of Medicine, 335, $1001-1009$.

Scandinavian Simvastatin Survival Study Group (1995) Baseline serum cholesterd and treatment effect in the Scan dinavian Simvastatin Survival Study (4S). Loncet, 345, 1274.

Shepherd, J., Cobbe, S. M., Ford, 1., et ol (1995) Prevention of coronary heart disease with pravastatin in men with hypercholesterolemia. New England journal of Medicine, 333. 1301-1307.

Wardle, J., Armitage, J., Collins, R., et el (ISs) Randomised placebo controlled trial of effect on mood of lowering cholesterol concentration. British Medical journal, 313. 75-78.

F. Corrigan Argyll \& Bute NHS Trust, Lochgilphead. Argyll PA31 8LD

\section{Perpetrators of child sexual abuse}

Sir: We wish to challenge the unreferenced statement by Hilton \& Mezey (1996) that the most common form of sexual abuse is fatherdaughter incest. Data published recently from our community study of adult New Zealand women showed that when 251 women reported child sexual abuse (CSA) of all types occurring when they were under 16 years of age, 22 recalled the perpetrator to be a father or father figure (i.e. stepfather, adoptive father or mother's live-in boyfriend), 75 recalled other relatives (of whom 21 were brothers), 116 acquaintances of the family and 38 strangers unknown to the girl (Romans et al, 1996). When accounts of CSA were restricted to those which involved contact with the girl's genitalia, the perpetrators included 22 father figures, 62 other relatives, 31 family acquaintances and 15 strangers. A similar profile was found for all CSA occurring when the victim was aged 12 years and under: the reported perpetrators included 17 fathers/father figures (12 biological fathers and five stepfathers), 69 other male relatives (of whom 16 were brothers) 81 acquaintances of the family and 26 strangers (unpublished data).

We are not the first group studying CSA to report such a pattern of perpetrator identity. Wyatt (1985) reported the following perpetrator percentages among 158 White American women: father/father figure $6 \%$, other relatives $13 \%$ (of whom brothers comprised $3 \%$ ), family acquaintances $30 \%$ and strangers $51 \%$. The equivalent figures for the 147 African-American women in that study were father/father figure $10 \%$, other relatives $19 \%$ (of whom brothers comprised 3\%), family acquaintances $34 \%$ and strangers $37 \%$.

All studies, of which we are aware, reporting a random community design, show substantial numbers of non-father relatives and friends or acquaintances of the victim's family to be perpetrators. Reliance cannot be placed on official judicial, health or welfare figures because of the now well-documented low rates of reporting. The large and important perpetrator categories of non-father biological relatives and family acquaintances need to be considered as they usually account numerically for more CSA than father figures, and the CSA they inflict can be intrusive and repeated (Romans et al, 1996).

We believe that it is important to correct this common misconception for at least two reasons. It may produce unwarranted scepticism by the clinician when dealing with 